\title{
DETERMINATION OF NATIONAL REFUGEE POLICIES USING SYSTEM DYNAMICS APPROACH
}

\author{
Vladimir Ninković, PhD \\ Faculty of Security Studies, University of Belgrade, \\ E-mail: vladimirninkovic@yahoo.co.uk \\ Ozren Džigurski, PhD \\ Faculty of Security Studies, University of Belgrade, \\ E-mail: odzigurski@gmail.com
}

\section{Abstract}

According to the recent UNHCR data, at the end of 2016, an unprecedented 65.6 million people around the world have been forced away from home. Among them are nearly 22.5 million refugees, over half of whom are minors. Figures in the report showed that, worldwide, most refugees - 84 per cent - were accommodated in developing or middle-income countries at the end of 2016, with 4.9 million people being hosted by the world's least developed countries. This huge imbalance reflects the lack of international consensus when it comes to hosting refugees. It also illustrates the need for countries and communities supporting refugees and other displaced people to be properly protected and supported, the absence of which can cause instability, have consequences for life-saving humanitarian work or lead to secondary displacement. Humanitarian protection, whether for refugees, asylum seekers, or internally displaced persons (IDPs), represents a key policy area for many major immigrant-receiving countries as well as nations bordering locations where war, political upheaval, or natural disaster have disrupted daily life. Refugee policy is a formal statement of, and proposed course of action in response to, a problem relating to protection, solutions or assistance for refugees or other populations of concern to the global refugee regime. With that objective, national refugee policy can be used to describe any course of action which intends to change a certain situation. National government uses policy to tackle a wide range of issues. In fact, it can make policies that could change laws and regulations in domain of security, economic, education, immigration, refugee protection etc. Think of policies as a starting point for national government to take a course of action that makes a refugee real life change. The paper presents a conceptual idea of definition of system archetype in the field of National protection refugee policies based on the system thinking. The basic idea is to point at the analytical potential of the System Dynamics (SD) concept in determination of National refugee protection policies by using the simulation approach. We will use the SD simulation approach, 


\section{Security}

which can provide an insight into dynamic processes of changes in the system and interaction of elements that define the activities pertaining to determination of refugee policies. The SD model is represented as a Causal Loop Diagram (CLD) showing the cause-consequence relations between system elements. Through computer simulation, the model developed using the CLD enables analysis of various scenarios as a basis for evaluation and decision making support in the field of National refugee protection policies.

Keywords: refugee crisis, refugee policy, system dynamics, system simulation

\section{Introduction}

At this point of time there are more refugees in the world than at any time since the end of the Second World War. The causes of contemporary displacement have become ever more complex, as conflict, violence and human rights abuses are increasingly intertwined with ethnic and religious animosities, acute poverty and deprivation, and environmental factors linked to climate change. The most relevant for the region is the movement of vast number of refugees and migrants from the Middle East and Northern Africa. Namely, the wave of demonstrations and protests, riots and civil wars known as The Arab Spring (Arabic: عيبرل|", ar-rabî̄ al-'arabī) and escalation of Syrian crisis in 2011 were trigger events for a great migrant flow from the Middle East and Africa towards Europe that intensified in 2014 and reached almost unimaginable dimensions during 2015 (Kešetović \& Ninković, 2016). In fact, the 2013 United Nations projected number of migrants was largely surpassed in 2015, accompanied with equally high growth rate. In 2015, it was assumed that the total number of migrants on the global level would reach a maximum of 237 million, which represents a drastic increase in comparison with the year 1990, when the total number of migrants amounted to "only" 154 million (Simeunovic, 2015). Every attempt to quantify the number of migrants can give only a momentary and shaky figure that may be outdated after several days.

Thus, Europe is currently witnessing a mixed-migration phenomenon, in which economic migrants and asylum seekers travel together and these groups overlap. This phenomenon is further exacerbated by the inconsistent methods with which asylum applications are often processed across the EU (Park, 2015).

An alarming number of refugees are living in limbo because of conflicts that have gone on for years or even decades, with no solutions in sight. More than half of the world's refugees are children and, if nothing changes, their children will be refugees, too. Whose responsibility are refugees? Why are they so often regarded as a threat, rather than as people who are threatened? How to determine refugee protection policies on a national and international level?

Despite their large numbers in historically and geographically various settings, all migrations show similar traits which enables creation of migration models and simulations. In the 


\section{Secuurity}

following pages we will present a conceptual idea of definition of system archetype in the field of National protection refugee policies based on the system thinking. The basic idea is to point at the analytical potential of the System Dynamics (SD) concept in determination of National refugee protection policies by using the simulation approach. We will use the SD simulation approach, which can provide an insight into dynamic processes of changes in the system and interaction of elements that define the activities pertaining to determination of refugee policies. The SD model is represented as a Causal Loop Diagram (CLD) showing the cause-consequence relations between system elements.

\section{Refugees and their protection}

According to the recent UNHCR data, at the end of 2016, an unprecedented 65.6 million people around the world have been forced away from home. Among them are nearly $\mathbf{2 2 . 5}$ million refugees, over half of whom are minors. Figures in the report showed that, worldwide, most refugees - 84 per cent - were accommodated in developing or middle-income countries at the end of 2016, with 4.9 million people being hosted by the world's least developed countries. This huge imbalance reflects the lack of international consensus when it comes to hosting refugees. It also illustrates the need for countries and communities supporting refugees and other displaced people to be properly protected and supported, the absence of which can cause instability, have consequences for life-saving humanitarian work or lead to secondary displacement.

Tens of millions of people around the globe have been forcibly displaced by conflict, natural disaster, or persecution, seeking refuge either within or beyond the borders of their country. According to the UNHCR, on whose refugee policy methodology we will heavily rely in this paper, people become refugees when the rule of law in their home countries breaks down. They depend on the rule of law to find protection in other countries. They hope for the restoration of the rule of law in their own countries, to be able to return home one day (UNHCR, 2017). Humanitarian protection, whether for refugees, asylum seekers, or internally displaced persons (IDPs), represents a key policy area for many major immigrant-receiving countries as well as nations bordering locations where war, political upheaval, or natural disaster have disrupted daily life.

There is an ongoing debate how to call the people who move into Europe due to the wars and crises in the Middle East, Near East and North Africa, i.e. whether they can be classified as refugees, migrants or asylum seekers. This is not just a linguistic question, as according to the international law, refugees and migrants can be treated differently. Namely, countries are free to deport migrants who arrive without legal papers, which they cannot do with refugees under the 1951 UN Convention (Sengupta, 2015). Therefore, for many EU politicians there is an incentive to qualify everyone fleeing to Europe as migrants instead of refugees.

Under the UN Refugee Convention on the Status of Refugees from 1951, an asylum seeker is a person fleeing persecution or conflict, and therefore seeking international protection. Strictly 


\section{Securitity}

speaking, a refugee is an asylum seeker whose claim has been approved. However, the same convention defines a refugee as any person who "owing to well-founded fear of being persecuted for reasons of race, religion, nationality, membership of a particular social group or political opinion, is outside the country of his nationality and is unable or, owing to such fear, is unwilling to avail himself of the protection of that country; or who, not having a nationality and being outside the country of his former habitual residence as a result of such events, is unable or, owing to such fear, is unwilling to return to it." (UNHCR Convention and Protocol, 2011). Therefore, in the eyes of the UN Syrian nationals enjoy prima facie refugee status. They are so recognized as it is too dangerous for them to return to their own country, and for them denial of asylum has potentially deadly consequences (Edwards, 2015). An economic migrant is, on the contrary, a person whose primary motivation for leaving is economic gain. Lately, the term 'migrant' is seen as an umbrella term for all three groups (Park, 2015), although according to the UNHCR this is not justifiable (Edwards, 2015).

According to the UNHCR "So, at UNHCR we say 'refugees and migrants' when referring to movements of people by sea or in other circumstances where we think both groups may be present - boat movements in Southeast Asia are another example. We say 'refugees' when we mean people fleeing war or persecution across an international border. And we say 'migrants' when we mean people moving for reasons not included in the legal definition of a refugee" (Edwards, 2015).

The countries are bound to provide protection to refugees on their territory by the UN 1951 Convention and UN Protocol of 1967. International human rights obligations also pressure national states to extend relevant human rights to refugees. "Even states that are not party to the Convention or Protocol are bound by the principle of non-refoulement, which is considered a norm of customary international law and as such is binding on all states". As the phenomenon of refugees is inherently international, international cooperation is of the utmost importance. This particularly holds true in instances when developing countries, are called upon to host large numbers of refugees for long periods of time, without necessarily having sufficient resources. Mass influxes and protracted refugee situations place a tremendous strain on host countries. Other countries can make an important contribution by providing financial and technical assistance, and by participating in refugee resettlement programs.

States have additional responsibilities towards certain asylum seekers and refugees on account of their age, sex, disability and/or other factors. Initiatives to secure the protection of refugees and asylum seekers need to take full account of the diversity of this population. UNHCR's Executive Committee has recognized that some asylum seekers and refugees are particularly at risk. Drawing on international human rights standards, it has adopted three Conclusions that provide the framework for a holistic approach to the needs of the following, potentially overlapping, categories:

- Children;

- Women and girls;

- Persons with disabilities; and

- Other persons with specific needs. 
For instance, UNHCR gives clear guidelines for the protection of children refugees. Some of the measures include:

- Ensuring that birth registration and documentation are provided for all children;

- Putting in place procedures to prevent the separation of children from their families, and to facilitate tracing and family reunification for those who have become separated;

- Providing and monitoring alternative care and accommodation arrangements for unaccompanied and separated children;

- Ensuring a secure environment for children; and

- Supporting durable solutions for children

\section{Global, Regional and National Refugee Policies}

At the global level, the main provider of protection to refugees is United Nations High Commissioner for Refugees - UNHCR, a subsidiary organ of the United Nations General Assembly. It was established as of January 1,1951 to provide international protection to refugees and, together with governments, to seek solutions to their plight. Over the years, the UN General Assembly and the UN Economic and Social Committee (ECOSOC) have expanded UNHCR's responsibilities to include functions and groups that were not covered by the original Statute. This expansion relates to refugees who have returned home voluntarily (returnees), to stateless people, and to internally displaced persons.

UNHCR's mandate to provide protection includes material assistance, which can often help make it possible for a country to accept refugees, since it relieves some of the financial burden. Effective legal protection is essential for refugees, but they must also be able to meet their basic needs - shelter, food, water, sanitation, medical care, and education. Over the years, UNHCR has increasingly been called upon to provide protection and assistance in countries where there is ongoing conflict. This trend started in the Balkans and the Great Lakes region of Africa in the 1990s. Today, UNHCR is involved in the UN system's response to almost all complex emergencies.

The International Committee of the Red Cross (ICRC) is also a key protection actor. An independent, neutral organization, the ICRC works to ensure humanitarian protection and assistance for victims of armed conflict, and to promote respect for international humanitarian law. The International Federation of Red Cross and Red Crescent Societies (IFRC) comprises 190 national Red Cross and Red Crescent societies. The Federation provides humanitarian relief to people affected by emergencies around the globe.

Another important actor is the International Organization for Migration (IOM), an intergovernmental agency on migration. IOM works in four broad areas of migration management: migration and development, facilitating migration, regulating migration and responding to forced migration. 
Regional parliaments are also involved in refugee protection. In Europe, for instance, both the Parliamentary Assembly of the Council of Europe and the European Parliament (the directly elected legislative body of the European Union) are active on refugee issues, and both groups are Associate Members of the Inter-Parliamentary Union.

The Parliamentary Assembly has developed guidance on numerous issues that relate to refugee protection, such as alternatives to detention, managing mixed migratory flows, tackling intolerance, the right to work for asylum seekers and standards to apply in the context of return measures. The Parliamentary Assembly also monitors and reports on the situation of asylum seekers and refugees in the 47 Member States of the Council of Europe.

The European Parliament is involved in the drafting and approval of European Union law agreed as part of the common European asylum system. Beyond its legislative role, several Parliamentary committees, especially the Committee on Civil Liberties, Justice and Home Affairs, are engaged in a wide range of other refugee-related matters.

Down to the national level, national parliaments have a central part to play in the creation and maintenance of a national legal framework for protecting refugees. Parliamentarians are responsible for reviewing policy documents and preparing and approving legislation that is in line with international standards. They also appropriate funding for government departments and agencies, and can help to encourage a positive response to refugees from citizens (UNHCR, 2017:35).

In addition, at the national level, judges have a vital role in refugee protection. Their decisions contribute to the consistent and sound interpretation and application of relevant standards and can help to bridge protection deficits in contexts where political, administrative and legislative processes may be weak. Finally, national human rights institutions (NHRIs) exist in more than 100 countries. While operating independently from the State, they make important contributions to protecting and monitoring respect for the rights of asylum seekers and refugees. NHRIs may be human rights commissions or ombudspersons. For the implementation of the international and national policies often a separate national body is formed, for instance, in Serbia it is the State Commissariat for Refugees and Migrations.

Generally, there are two aspects of the refugee management - providing them protection through the establishment of the asylum system, and managing their influx through implementing various policies related to the border management.

A State asylum system is the totality of strategies, laws, policies and action plans, in combination with adequate resources and institutions, which form a State's response to asylum seekers and refugees. The establishment of national asylum systems makes it possible for States to respond to refugee influxes in a predictable manner and to limit the potential for abuse. Establishing a national asylum system helps a State to manage the arrival of persons who claim to be in need of international protection, and enables asylum seekers and refugees to enjoy the rights to which they are entitled under international law. Developing a State asylum system involves establishing a legislative framework and related policies, strategies and action plans to enable the government to fulfill its international obligations to asylum seekers and refugees. 
Another aspect of national policies towards refugees relates to the border management and regulation of the entry of refugees and the deportation. As a general rule, no country is obliged to allow foreigners to enter its territory. It is one of the core elements of sovereignty that a State may decide under what circumstances it will permit non-citizens to enter. As an exception to this rule, States are obliged to respect the principle of non-refoulement contained in international refugee law and human rights law. That principle establishes that no one shall be returned to a territory where his or her life, physical integrity or freedom would be threatened. Properly functioning border management systems can help States to regulate the entry of foreigners, comply with their international refugee protection obligations and deny a "safe haven" to persons responsible for terrorism, war crimes and crimes against humanity.

Just as States have a right to control the entry of foreigners to their territory, as part of the exercise of their sovereignty, they are also entitled to remove or deport foreigners who are present without authorization (and in specific circumstances, those legally present). In so doing, however, they are bound by their obligations under international refugee and human rights law and in particular by the principle of non-refoulement. While deportation or removal provisions may be applied to foreigners in general, the expulsion of a legally present refugee is only permitted in exceptional circumstances, as explained in Articles 32 and 33 of the 1951 Convention. Furthermore, provisions should be made to allow the affected individual a reasonable period of time to seek legal admission into another country. An asylum seeker is protected by the principle of nonrefoulement for the duration of the asylum proceedings. If he or she is recognized as being in need of international protection, any previously issued expulsion order should automatically lose its validity.

\section{System dynamics in policy design and analysis}

Invented in mid 1950s by Jay Forrester of the Massachusetts Institute of Technology (MIT), SD is defined as a "computer simulation of continuous, non-linear feedback systems, emphasizing an endogenous point of view". SD is an approach applicable to policy analysis and design, based upon feedback principles and computer simulation. It applies to dynamic problems arising in complex social, managerial, economic, or ecological systems - i.e. any dynamic systems characterized by interdependence, mutual interaction, information feedback and causality. SD can deal with dynamic policy problems of systemic, feedback nature, which can arise from the interactions between system variables and from the feedbacks between the managerial actions and the system's reactions. The purpose of an SD study is to understand the causes of a dynamic problem, and then search for policies that alleviate/eliminate them (Forrester J.W. 1961).

Feedback thinking is a central concept in the SD approach. This means that there is a closed causal chain, a closed loop of mutual cause-and-effect, so that an effect perpetuates until it influences back to its initial cause, after having passed one or any number of variables before. 


\section{Securrity}

The second key concept refers to the important status of stocks and flows. As soon as SD models are used for simulation it needs to be identified whether a variable is a stock or a flow variable. Stock variables are accumulations and indicate the status of the system through time, whereas flows represent the rate of change: they increase or decrease a stock over some time interval, being either inflows or outflows.

The objective for creation of a SD model is to develop a hypothesis, a theory that explains the causes behind the problematic dynamics. In the first step, this must be an "endogenous" explanation. Later, this hypothesis is converted to a formal simulation model and the validity of the hypothesis can be tested.

SD theory views the refugee problems as a complex social, political and economic system formed by the interactions of individual efforts to achieve certain goals. Many institutions and individuals can take actions that appear to satisfy their own objectives; the aggregation of these efforts constitutes a complex refugee social system. SD provides a theory that embraces a conceptual understanding that refugee system as a whole. It can facilitate analysing various activities as interrelated functions. Therefore, it is a convenient management tool for refugee policy analysis.

Through simulation analyses of SD models, it is possible to study the effects of alternative programs and policies about refugee-related issues as a whole. The model then allows us to analyse the system's response to programs and reach conclusions about policy decisions. An SD model permits computer simulation of alternative policies to improve refugee management. A fuller understanding of how to use SD may be explored by additional modeling and the analysis of policies in specific problems. Policy testing can help to achieve goals for many activities about refugees issues.

SD approach presents a model describing the major internal forces controlling the refugee flows, protection and asylum (Ninković et al, 2017). According to that SD approach became the basis of a major research effort that has influenced many government refugee policy decisions.

Public policy problems have numerous characteristics that complicate both development and implementation of effective policies. SD models can play an important role in overcoming the above issues. An approach in development public policy in the field of refugee planning and management represents the use of system thinking principles with the application of SD tools. This approach can be used for developing a computer simulation that can provide an insight into dynamic processes of changes in the system and interaction of components that define the activities pertaining to refugee policy development. According to that SD approach may became the basis of a major research effort that has influenced many government and community refugeepolicy development. 


\section{System dynamics model and Causal Loop Diagram (CLD) in Refugee Policy Design}

The key step in generating a conceptual model is the construction of a CLD. The SD conceptual model for development refugee policies is represented as a CLD showing the causeconsequence relations between complex refugee system components (Figure 1). The CLD model presents a conceptual idea of definition of system archetype in the field of refugee policy, based on the system and resilience thinking. Among others, one of the basic ideas is to point at the analytical potential of the resilience concept in refugee domain planning by using the simulation approach.

On this CLD we singled out three domains that play important roles in urban refugee policy making - Security, Resilience and Refugees status. In addition, in creation of refugee policies important role can belong to other subjects, such as public, civil and profit sectors and international organizations.

On the basis of Security assessment and Resilience assessment, as well as on the refugees socially and economic status, the decision on change of refugee policies is made with the object of achieving and maintaining the required national security level. Taking into account that the security aspect is among key factors, the Decision making system (DMS) among others, is used for security management. This sector, with the assistance of the separate Emergency warning system block (EWS), for monitoring and identification of emergency situations, threats and crises, together with the application of all other parameters in the system, brings about decisions on security management aimed at the maintenance of security stability. Apart from that, EWS has an important role in monitoring and prevention of potential terrorist activities planned or performed by individuals or groups of refugees. After the detection of the surpassing of critical values of those indicators by the EWS, a signal is sent to the DMS for an urgent reaction with the aim of removal of consequences caused by serious disturbances. In addition, the EWS warning signals can lead to the change of the policies of refugees planning and management.

Apart from the required expert knowledge and political power, DMS contains also ICT and other technological devices and means used for gathering information for bringing adequate decisions. This equipment may be also used as a support in the realization of some decisions.

As already mentioned, apart from the impact on the national security, the refugees social and economic status has a significant impact on the creating refugees management policies. In addition, on the formation of a comprehensive set of refugee policies, the Public Sector has an important influence, followed by the civil sector and profit sector. In this case, Public Sector contains various stakeholders in the surroundings - international and national institutions. As shown in the first part of the paper, the dominating role belongs to UNHCR that develops standards and recommendations for refugee management.

Civil sector is comprised of various forms of non-governmental organizations (NGOs), religious and citizen groups. $\mathrm{NGO}$ s are organizations, "characterized primarily by humanitarianism or cooperation, rather than commercial objectives, that pursue activities to relieve suffering, promote the interests of the poor, protect the environment, provide basic social services, or 


\section{Securiaty}

undertake community development" among other things (World Bank 1989). There are different levels of organization that can be observed when looking at various NGOs. The most organized organizations tend to be established, large, international NGOs which often have offices in multiple locations, and in addition to their field work, are also grantors to smaller NGOs (Autesserre, 2014). In the middle are established, domestic NGOs which also tend to focus their activities at the national level. They may or may not receive funding from state or international donors. Finally, there are the younger, more specialized organizations that tend to be organized around a specific task or purpose and operate predominantly at the local level.

Finally, Profit sector may be interested in having a say in making of refugee policies guided either by their security concerns, or observing refugees as potential employees or competition. Thus, they may press for relaxing of issuing work permits, or, on the contrary, stricter regulations. In addition, corporations, companies and small and medium enterprises can provide assistance in refugee management by providing various goods and resources and by organizing legal transport of refugees.

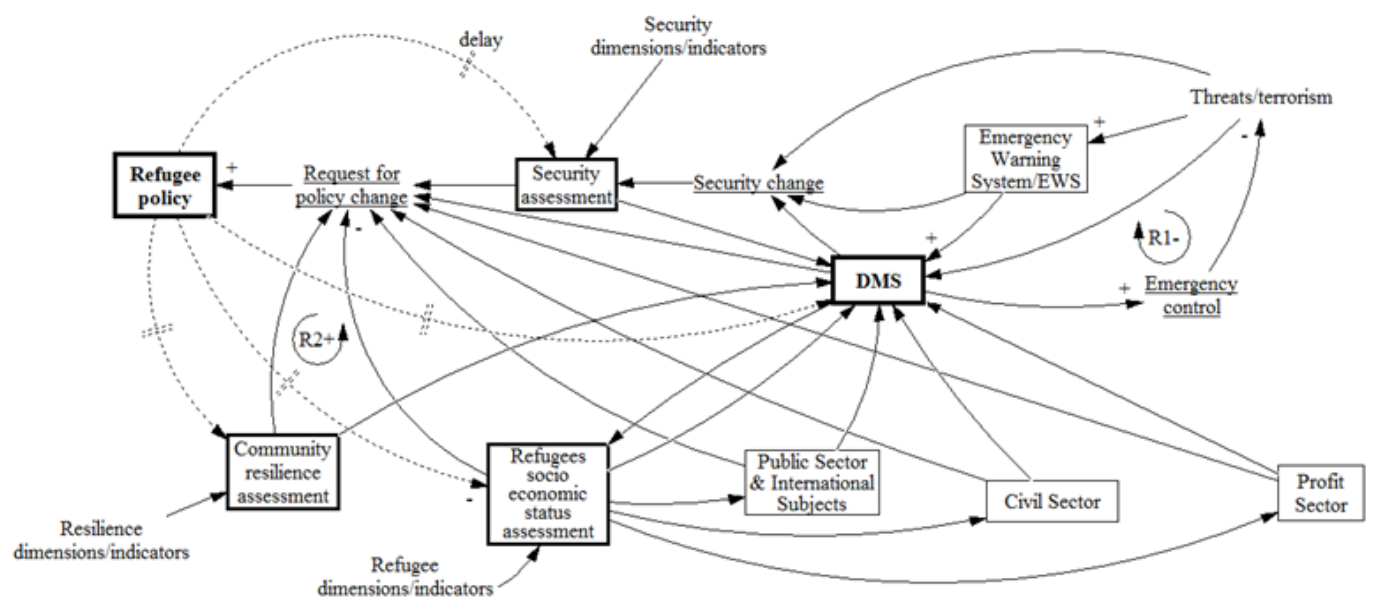

Figure 1. Causal Loop Diagram of the SD conceptual model for refugee development policies.

Several closed loops can be observed on the diagram, on whose basis the influence of different factors on refugee policy can be assessed. For instance, by applying the SD principles it can be concluded that the loop R1 (DMS-Emergency control-Threats - EWS-DMS) has a stabilizing character, from the security aspect. On the contrary, the loop R2 (Refugee policy-Refugee socioeconomic statusassessment-Requestfor policy change-Refugeepolicy) has a destabilizing influence, caused mainly due to delays in adopting adequate refugee policies. Other loops in the CLD can be analysed in a similar manner. Consecutively, we can conclude that security stability is influenced by timely and adequate security control and decision. In other words, the delay in adopting adequate refugee policies can lead to system instability and even insecurity. 
Time delays often play an important role in the dynamics of systems. Significant time lags may intervene between causes and their effects. There are two general categories of time delays in SD: material/financial delays and information delays. An important consequence of having delays in structures is that they are potential sources of oscillatory or unstable behaviour. Due to that reason, depending on expected and realistic disturbances and threats, DMS plays the main role in the stabilization of the refugee environment, by adoption of predictive and timely measures.

The showcased methodology, based on the SD principles, can be operationalised for the use in real conditions via adequate software tools for simulation of dynamic systems. ${ }^{78}$ This software tool enables the direct formation of simulation model on the basis of CLD that aids in visualizing how different variables are interrelated in the system.

Starting from the conceptual CLD model (Figure 1), the software internally realizes all mathematical relations of the model and forms a simulation model. Also, this software tool generates the system of complex nonlinear differential-integral equations, which represent a mathematical model of the analysed dynamic system.

Generally, all variables in the model have the form of complex mathematical expressions that represent dependence of certain system functions on different factors and time (Ninković et $\mathrm{al}, 2017)$.

For instance, the variable Security_assessment, representing security situation of the environment in which the refugee presence is observed, can have the following general form:

Security_assessment $(t)=f($ level of crime, risk assessment, spatial characteristics...t $)$.

In a similar fashion, other variables related to the refugee activity can be represented in the model:

\section{Community_resilience_assessment $(t)=f($ support resources, organizational structure, preparedness activities...t).}

The World Resources Institute defines resilience as 'the capacity of a system to tolerate shocks or disturbances and recover' and argues that this depends on the ability of people to 'adapt to changing conditions through learning, planning, or reorganization' (World Resources Institute, 2008). Resilience, therefore, can be related to the way that societies adapt to externally imposed institutional, environmental and economic changes, caused by refugee presence and their activities in certain location.

Refugees_socio-economic status_assessment $(t)=f$ (migration flow, socio/economic factors, healthstatus,..., $t$ ).

Refugees' socio-economic status in certain locations can be determined on the basis of their numbers and migration trends at this and other locations. The status is determined by the social position and economic factors of refugee groups and individuals. Also, an important factor is the health situation of refugees.

\footnotetext{
${ }^{78}$ For this simulation we used Vensim software, available for download on http://vensim.com.
} 


\section{Decision_making $(t)=f$ (refugees activities monitoring, refugees activities control, security control..., $t$ ).}

The decisions on the managing of refugee activity are made by DMS. These decisions are made on the basis of the monitoring of refugees activities and status, and also on the basis of the adopted policies. Among important activities of this sector is the security situation control, which can be jeopardized by illegal activities performed by refugees or other connected actors.

Refugee_policy $(t)=f($ refugees adoption, asylum-readmited decision, refugees control,..,t).

On the request for the amendments of the refugee policy, the revision or modification of the existing policies is done. The new policies can be adopted in case when new circumstances arise. The demands for the change of refugee policies are based on the security, resilience and refugees status assessment, and on the request of other relevant actors coming from public, profit and civil sector, as previously mentioned. Certainly, the request for the changes of refugee policies can come from DMS, when on the basis of the existing refugee policies and significantly changed circumstances, efficient management of refugee activities becomes impossible.

On that basis, all variables $\mathrm{Vi}$ in the model may be expressed in the following equation form:

$V i=F 1 c 1+F 2 c 2+\ldots . . F n c n$; where

$\mathbf{F j}(\mathbf{t})$ are non-linear functions or coefficients representing system components, which can be time dependant; and

cj represent weighting parameters.

Determination of factors and parameters of a concrete refugee system is done on the basis of the system analysis, statistical data, empirical and expert knowledge. Also, the weights parameters are adjusted during experimental testing of the model using the standard calibration procedure. For that reason, data may be collected from different sources and real world events and compared with the outcome of the model simulations. For instance, the outcomes closest to the observed historic data are selected and used in the model for further experimental simulations.

The whole quantification process, i.e. the transformation of the conceptual into simulation model with real parameters, consists of complex activities and requires expert and team work, with the participation of many actors with different profiles and backgrounds. On the basis of the real model, the same approach can be used for assessment of various refugees environment protection scenarios from different threats and hazards, as an aid in decision making about the choice of an optimal strategy (Simonović, 2005). In addition, community resilience and SD simulation approach may be dominantly used for determination of refugee development policies.

The complexity of the process of identification of components and parameters of the real model can be demonstrated through the example of determination of indicators of refugee integration. 


\subsection{Indicators of refugee integration}

In order to select indicators for measuring the well-being of refugees and persons of concern, UNHCR has engaged in a wide consultative process involving UNHCR staff both at Headquarters and at Field Offices, relevant agencies and non-governmental organization partners. Technical officers provided invaluable contributions in revising the indicators' list, and policy units reviewed the indicators and modules to make sure that they addressed UNHCR strategic priorities and age, gender and diversity mainstreaming concerns (UNHCR, 2006).

The development of a refugee integration evaluation tool is part of a necessary strategy for protection in Europe where Integration is the most common durable solution for refugees.

While the process of refugee status determination in its legal and social aspects usually involves several institutions of a Government, refugees' integration is a multidimensional complex process. It necessitates actions from numerous ministries, different levels state administration all the way down to municipalities and from a large variety of non-governmental stakeholders such as NGOs, employers, trade unions, schools, education providers of language and vocational skills, health care providers, the banking system, landlords and many others. Therefore it has been very difficult to evaluate the impact and the cost effectiveness of integration measures so far.

In each country UNHCR needs to identify persons with different areas of expertise (i.e. naturalisation, employment, health,...) and different types of expertise (i.e. legal, policy, financial, research,...). Legal experts, policy analysts, financial officers for state and non-state actors, project evaluators and researchers will cooperate on the project. Provided commitment from all Governments involved and sufficient resources, piloting the evaluation across the Central European region will take some 18 months. Once established, however, regular follow-up surveys are expected to be considerably faster.

One of the projects from the domain of the Refugee Integration Evaluation Tool was realized in Belgium (UNHCR, 2013). Namely, the Migration Policy Group, a Brussels based think tank, in close collaboration with the Regional Representation developed a comprehensive Refugee Integration Evaluation Tool (MIGPOL, 2016).The tool helped create a data base with over 200 indicators requiring inputs from governmental and non-governmental stakeholders alike.

The indicators, both quantitative and qualitative, are grouped under four headings:

- 16 indicators on general considerations (impact of reception conditions on integration, mainstreaming of refugees into general policies, ...)

- 75 indicators on legal integration (residency rights, family reunification, ...)

- 84 Socio-economic indicators (housing, employment, health, ...)

- 46 socio cultural indicators (language learning, participation, ...)

The tool covers every aspect of refugee life, from the use of skills and qualification in their current employment or school enrolment of children to more administrative issues such as government budgets for professional and cultural orientation. 


\section{Conclusion}

Mass migrations have been a constant throughout the human history. However, due to the globalization and developments in technology, especially in transport their frequency and volume intensified in the recent decades. At the end of 2016 most refugees (84\%) were accommodated in developing or middle-income countries, with 4.9 million people being hosted by the world's least developed countries (UNHCR, 2017). This huge imbalance illustrates the need for countries and communities supporting refugees and other displaced people to be properly protected and supported, the absence of which can cause instability, have consequences for life-saving humanitarian work or lead to secondary displacement.

Humanitarian protection, whether for refugees, asylum seekers, or IDPs, represents a key policy area for many major immigrant-receiving countries as well as nations bordering locations where war, political upheaval, or natural disaster have disrupted daily life. Another policy area that must be taken into account is the one related to the issues of managing the influx of migrants border management, as well as deportation policies.

In this paper we proposed the SD method (stock and flow diagram) for creation of decision making model for refugee policies at the national level. The model that we offer is of conceptual nature. This is a pilot model, in the early stage of development, as the development of complete and concrete SD migration models is a complex and time-consuming task that would require engagement of a multidisciplinary team of experts. The model was built and simulations performed using the Vensim software modeling tool, the results of which may be used for prediction purposes, creation migration management scenarios, as well as for the risk and resilience assessment of the migrant routes. 


\section{References}

1. Autesserre S. (2014). Peaceland:Conflict Resolution and the Everyday Politics of International Intervention. New York: Cambridge University Press.

2. Edwards A. (2015) "UNHCR viewpoint: 'Refugee' or 'migrant' - Which is right?" Accessed on 12.5.2018. URL: http://www.unhcr.org/55df0e556.html

3. Forrester J.W. (1961). Industrial Dynamics. MIT press, Cambridge, MA.

4. Kešetović Ž. \& Ninković V. (2016) "Migrants and Local Extremists in South-Eastern Europe", in Čaleta, D \& Shemella, P (eds.) Comprehensive Approach to Counter-Radicalism and Extremism - Future Challenges for Counter Terrorism Process. Ljubljana, pp.101-114.

5. Migration Policy Group. (2016). Refugee Integration Tool. Accessed on 20.5.2018. URL: http://www.migpolgroup.com/diversity-integration/refugee-integration-tool/

6. Ninković V., Džigurski 0. \& Keković Z. (2017) "Dynamic Migration Flow Modelling", in: Security Dialogues, Vol 8, No.1-2. Skopje, St. Cyril and Methodius University, pp.149-169.

7. Park J. (2015) "Europe's migration crisis". CFR Backgrounders. Council of Foreign Relations. Accessed on 12.5.2018. URL: http://www.cfr.org/migration/europes-migration-crisis/ p32874

8. Sengupta, S. (2015) Migrant of refugee? There is a difference, with legal implications. The New York Times. Accessed on 8.5.2018. http://www.nytimes.com/2015/08/28/world/ migrants-refugees-europe-syria.html?_r=0

9. Simeunovic D. (2015) "Migracije kao uzrok političkih anomalija u Evropi"/"Migrations as reason for the political anomalies in Europe" in: NBP - Journal of Criminalistics and Law, Vol XIV, No. 3. pp.1-18

10. Simonovic S.P., Ahmad S. (2005) "Computer-based Model for Flood Evacuation Emergency Planning" in: Natural Hazards. 34: 25-51

11. UNHCR (2006). Practical Guide to the Systematic Use of STANDARDS \& INDICATORS in UNHCR Operation, SECOND EDITION.

12. UNHCR. (2011) Convention and Protocol relating to the status of the refugees.

13. UNHCR (2013). Refugee Integration Evaluation Tool, Helping Governments measure impact of integration policies.

14. UNHCR (2017). A Guide to International Refugee Protection and Building State Asylums. Handbook for Parliamentarians, No.27.

15. World Bank. (1989). Involving Nongovernmental Organizations in World Bank-Supported Activities. Rep.No.14.70.

16. World Resources Institute, United Nations Development Programme, United Nations Environment Programme, and World Bank. (2008). World Resources 2008: Roots of Resilience - Growing the Wealth of the Poor, Washington DC, World Resources Institute. 